\title{
As razões do produtivismo: fricções intelectuais e capitalismo ficcional ${ }^{1}$
}

\author{
Rose de Melo Rocha' \\ I - ESPM \\ São Paulo (SP), Brasil
}

Resumo: Este ensaio retoma o debate sobre produtivismo, localizando algumas de suas bases de consolidação no Brasil. Opõe e distingue a produtividade científica da sedução produtivista. Finalmente, apresenta a metáfora da fricção para compreender o lugar possível da produção de conhecimento na contemporaneidade, desvendando as lógicas do capitalismo ficcional.

Palavras- chave: produtivismo; produtividade; capitalismo

Abstract: The reasons of produtivism: intellectual frictions and fictional capitalism - This paper resumes the debate on productivism, locating some of its consolidation bases in Brazil. It opposes and distinguishes scientific productivity from productivist seduction. Finally, it presents the friction metaphor to understand the possible place of knowledge production on contemporaneity, unraveling the logics of fictional capitalism.

Keywords: productivism; productivity; capitalism

O debate sobre produtivismo acadêmico teve início no Brasil no final da década de 80, quando a Reitoria da Universidade de São Paulo (USP) tornou pública, através de informações fornecidas à reportagem do jornal Folha de $S$. Paulo, uma lista de professores considerados improdutivos ${ }^{2}$. Mais de três décadas se passaram desde este episódio e 4a discussão ainda prossegue, embora não tenha gerado impactos mais significativos no que tange às métricas adequadas à avaliação da produtividade de professores universitários, em especial dos que recebem verbas públicas em apoio às investigações que desenvolvem. Esta preocupação mobiliza fortemente setores científicos, inclusive aqueles articulados

1 Retoma-se, em versão ampliada e modificada, o conteúdo de $\mathrm{X}$ proferida junto ao $\mathrm{X}$, em X.

2 Esta lista se apoiava em critérios exclusivamente quantitativos para definir a improdutividade de um pesquisador. 
às Ciências Exatas e da Saúde, que um olhar menos atento poderia imaginar favoráveis a quantificações estritas. Contudo, este não é um pensamento único, ainda que possa ser dominante.

As Ciências Humanas não se furtam a analisar tais questões. Falando mais especificamente de nosso campo de estudo, a comunicação, França e Prado (2013), pesquisadores experientes, e antigos representantes de área junto ao $\mathrm{CNPq}$, se debruçam sobre alguns fundamentos desta questão ao analisar os desafios e o compromisso social da pesquisa em comunicação no Brasil. Os autores são enfáticos ao apontar "o imperativo ditatorial que rege o mundo acadêmico nos dias atuais: publish or perish." (FRANÇA e PRADO, 2013, p.79). Diante disto, localizam alguns desafios: "a questão da qualidade; a abertura e compartilhamento da reflexão; o compromisso social do conhecimento; nossa inserção no cenário mundial." (idem). Comparando quantidade X qualidade, são bastante cautelosos ao afirmar que

[n]ão há nenhuma evidência empírica de que publicar muito aumenta a qualidade, ou sequer que o grande número de publicações garanta ao autor uma posição de referência. Ao contrário, deve-se temer pelo esvaziamento da qualidade provocado pelo produtivismo (acarretando produções superficiais e/ ou repetitivas), o que pode comprometer a credibilidade do autor. (FRANÇA e PRADO, 2013, p.80)

Sabemos da delicada teia de implicações do produtivismo como lógica e meta do trabalho acadêmico, assim como seus impactos nefastos em termos da fragilização na constituição de ações comprometidos com a agenda pública nacional e mundial. Tema como o da internacionalização é talvez um dos mais delicados braços desta movida e não constitui um consenso. Se França e Prado (2013) preocupam-se com a excessiva exogenia da base bibliográfica do campo da comunicação no Brasil, autores como Ladle (2012) mencionam a insularidade do conhecimento (dos BRICs, por exemplo) como um dado a se considerar. Nesta linha de argumentação, a insularidade incide em termos de uma excessiva autocitação nacional e, por decorrência, no baixo impacto internacional desta produção.

Mas existem aspectos convergentes nas diferentes posições. O prejuízo da saúde docente, que recebe a atenção de Zandoná, Cabral e Sulzbach (2014), e resultaria na síndrome de Burnout e no assédio moral, dentre outros, também é mencionado por França e Prado (2013), e se coaduna a outras ordens de preocupação. A ruptura das redes de solidariedade, a competitividade acirrada entre pesquisadores, instituições, programas e grupos de pesquisa são alguns dos impactos silenciosos e não menos determinantes na setorização, fragmentação, auto-referencialidade e individuação extrema na produção e divulgação do conhecimento ${ }^{3}$ :

3 Ver, a esse respeito, "O produtivismo acadêmico e seu impacto na pós-graduação stricto sensu: uma ameaça à solidariedade entre pares?". PATRUS, R., DANTAS, D. C. e SHIGAKI, H. B. Cad. EBAPE.BR, v. 13, n. 1, artigo

1, Rio de Janeiro, Jan./Mar. 2015. 
Estamos, no Brasil e em todo lugar, submetidos à necessidade de alcançar altos índices de publicação. O pesquisador se transforma num extrato intelectual, espécie de extrato contábil de publicações (como num extrato de banco). A rigor, não temos ouvido defesas do produtivismo. No entanto, vemo-nos enredados na teia que nos empuxa a aumentos de produção e interiorizamos a exigência com mais força do que a letra da lei, chegando alguns a se autoimpor uma dinâmica de trabalho que pode comprometer a qualidade da própria pesquisa (e sua qualidade de vida) (FRANÇA e PRADO, 2013, p. 80).

Santos (2010) indica a Reforma do Aparelho do Estado (MARE) como referente histórico do que denomina o crescente processo de mercantilização na educação superior. Iniciado na década de 90 vai refletir, paulatinamente, no reforço quantitativo como critério de análise da produção (mercadológica ou socialmente relevante). Este processo atingiu diretamente as universidades públicas, mas também se faz notar nas instituições privadas e nas confessionais. O movimento reformista levaria as IES a de certa forma cindir o ensino da pesquisa, instituindo a prática de busca por financiamento no aporte às iniciativas vinculadas à investigação científica. Esta "ciência ajustada" sinaliza para uma mutação da cultura universitária em sinergia com processos de mundialização do capital. Assim,

[o] trabalho formativo desempenhado pelas escolas e universidades passou a reforçar por meio das práticas pedagógicas e de pesquisa, os princípios do velho liberalismo econômico - individualismo, competitividade e produtividade - eixos que se tornariam posteriormente, orientadores do desenvolvimento de pesquisas no país (SANTOS, 2010, p. 149).

Pragmatismo e imediatismo tornam-se valores partilhados, com a naturalização do produtivismo:

O professor ideal agora é um híbrido de cientista e corretor de valores. Grande parte do seu tempo deve ser dedicado a preencher relatórios, alimentar estatísticas, levantar verbas e promover visibilidade para si e seu departamento. O campus vai se reconfigurando num gigantesco pregão. O gerenciamento do meio acabou se tornando fim na universidade. A ideia é que todos se empenhem no limite de suas forças (SEVCENKO, 2000, p.7; apud SANTOS).

A esta problemática se associam complicações correlatas: crise da autoria; fracionamento e epidermização da produção; declínio do pesquisador como intelectual e sujeito público. Outras leituras incidem diretamente nas relações entre produtivismo e sistema econômico, assumindo um viés de análise que politiza o debate. Debater o produtivismo desde uma proposta decolonial tem sido um caminho mais recente, que prevê o enfrentamento das imbricações de práticas e perspectivas neoliberais no âmbito do trabalho científico, colocando ainda em perspectiva a adesão reprodutivista a matrizes 
estadunidenses e eurocêntricas. Mignolo (2007), referendando-se em Quijano, vincula insubordinação civil a insubordinação epistêmica. É esta última um dos pilares do projeto decolonial:

\begin{abstract}
A opção descolonial é epistêmica, ou seja, ela se desvincula dos fundamentos genuínos dos conceitos ocidentais e da acumulação de conhecimento. Por desvinculamento epistêmico não quero dizer abandono ou ignorância do que já foi institucionalizado por todo o planeta [...]. Pretendo substituir a geo- e a política de Estado de conhecimento de seu fundamento na história imperial do Ocidente dos últimos cinco séculos, pela geo-política e a política de Estado de pessoas, línguas, religiões, conceitos políticos e econômicos, subjetividades, etc., que foram racializadas (ou seja, sua óbvia humanidade foi negada). Dessa maneira, por "Ocidente" eu não quero me referir à geografia por si só, mas à geopolítica do conhecimento.

Pensamento de fronteira ou epistemologia de fronteira é uma das consequências e a saída para evitar tanto o fundamentalismo ocidental quanto o não-ocidental. (MIGNOLO, 2007, p.4; p.11).
\end{abstract}

Tendo este cenário como perspectiva, nos propomos neste ensaio a abordar como demandas atuais do capitalismo - imperativo do desempenho, culto à performance, operacionalização do conhecimento, dentre outras daí derivadas - vinculam-se às razões do produtivismo. Compreender a condição de pressão e assujeitamento na qual constantemente nos vemos imersos é fundamental para vislumbrar horizontes outros de avaliação da produtividade acadêmica. Ou seja, não propomos um "vale tudo" no fazer científico, menos ainda nos parece defensável que pesquisadores engajados em universidades, centros de pesquisa e programas de pós-graduação neguem-se a compartilhar os resultados das investigações que desenvolvem, abrindo-se ao diálogo e igualmente às refutações.

Problematizar o produtivismo também não significa fazer o elogio da improdutividade, mas implica proceder a distinções. De modo a desenvolver esta hipótese, trazemos ao debate autores que questionam os modos de funcionamento e de construção das subjetividades na sociedade contemporânea, ao mesmo tempo em que se preocupam, de um ponto de vista epistemológico, com as implicações dos ditames neoliberais no campo acadêmico. Para tanto, nossa estrutura argumentativa compõe-se em dois eixos.

Inicialmente temos a metáfora da fricção ${ }^{4}$, saída epistemológica para compreender o lugar possível da produção de conhecimento crítico na contemporaneidade. Depois, analisamos características do capitalismo contemporâneo no que seria seu atual e paroxístico estágio, de acentuada crise e acirrada voracidade. O capitalismo, nestes termos, tem contribuído para a gestão das desigualdades, alimentando um programa

4 Não faço remissão ao problemático conceito de friç̧ão interétnica, popularizado no Brasil principalmente através do que foi proposto por Roberto Cardoso de Oliveira. 
sócio simbólico perverso, que desde a falência do Estado de bem-estar social, estimula a competitividade e a busca incessante por reconhecimento, fazendo do protocolo meritocrático um horizonte por demais frágil e falível de justiça ou igualdade social, inclusive no que toca, e tão diretamente, aos campos científico, intelectual e acadêmico.

Assim, colocam-se em circulação ficções magnetizantes e se produzem profundas fissuras - afetuais, na convivialidade, dando margem à emergência e à consolidação de paradigmas totalitários e individualistas. Há, pois, uma rede de valores, de axiomas, como preferem Deleuze e Guattari (2011), tomados e aplicados como se fossem ou naturais ou objetivos, e, portanto, automaticamente incontestáveis. A meritocracia vê-se subordinada a uma ordem discursiva facilmente atraída pelo elogio à ideia do esforço individual, da superação pessoal de limites, solapando subjetividades e adestrando coletividades.

Projetos coletivos, caros à produção do conhecimento científico e a seu avanço, tal como elaborado por filósofos da ciência como Lakatos (1998), perspectivas de colaboração solidária - entre iguais, mas também entre diferentes -, caras a uma política de subjetividade e de alteridade, a uma narrativa humanista do todos, como abordado por Serres (2015), naufragam pouco a pouco em um mar de desempenho, de regras mensuráveis, de estatísticas e/ou do número de aplausos obtidos. Meritocracia celebritie, tomando a inspiração de Rincón (2015). Serres (2017) é claro: sem distribuição do saber e sem inversão da perícia - que hierarquiza e isola os especialistas dos seres incautos - não há democracia possível. Completo: não há conhecimento implicado na consecução de um projeto democrático enquanto houver cientista dedicado à garantia e à manutenção de privilégios.

Em síntese, de um ponto de vista teórico procede-se à crítica do capitalismo, contemplando a perenidade histórica de seu regime axiomático, mas especificamente focando as matizes e desdobramentos (pós-modernos; pós-industriais) desta vocação em transformar o arbitrário ou circunstancial em verdade (científica, audiovisível). Considera-se existir na passagem da modernidade à pós-modernidade uma ênfase à produção e ao agenciamento político (por parte tanto do Estado quanto do Mercado) de formas culturais, estetizadas, estésicas e plásticas do mecanismo de abstratificaçãoliteralidade, e percebe-se como relevante o fato de ele se ancorar em materialidades tecno-comunicacionais. Não é demais esclarecer que não estamos aqui a fazer a detração da ficção ou o elogio apriorístico às ordens do documental. É necessário enfatizar que a produção de ficcionalidades (friccionais) pode e tem sido ferramenta potente de produção cultural e social contra-hegemônica, seja na arte, na cultura pop, nos ativismos ou na micropolítica cotidiana. Assim, é a ficcionalização sobrecodificada pelo capital a que em específico questionamos.

Foucault (1999) em As palavras e as coisas, analisando o caráter arbitrário da linguagem, denuncia os jogos de poder ancorados no conhecimento e seu efeito de ordenação do mundo. Neste sentido, toma-se a fricção como base epistemológica que nos guia naquilo que Martín-Barbero chamou certa vez de mapas noturnos; atribuo 
a esta fricção a possibilidade de transitar cognitiva, sensível e metodologicamente no campo de análise deste social cuja complexidade se faz crescente. Há que se friccionar a ficção capitalista, colocando-se o pesquisador em estados de ebulição e implicação constantes.

\section{A metáfora da fricção e as insubordinações epistêmicas}

Olhando a modernidade para, a partir dela, compreender a origem da condição pós-moderna, Bauman (1998) chama atenção para uma figura do mal estar que é, em sua gênese, paradoxal. Segundo explica, a tríade ordem/pureza/beleza, fundamental à empreitada da racionalidade instrumental encampada por alguns braços do projeto moderno, levou-nos a uma síncope higienista e a patologias de infantilização. Tornamo-nos, diz Bauman, bebês-chorões, temerosos de qualquer desvio de rota, de qualquer desordem, de qualquer imprevisibilidade e, muito visceralmente, de qualquer coisa, pessoa ou valor que nos seja desconhecido. Esta infantilização do sujeito é responsável por gerar o temor desmedido do outro, com o rechaço e o ódio aos estrangeiros. Não por acaso, o tema das migrações e das identidades de gênero irão ocupar tão intensamente os debates contemporâneos e viram quase que uma piéce de resistance para as epistemologias dissidentes e para perspectivar políticas de subjetividade.

Diante de tamanha fricção simbólica, e de tamanha alteração das sensibilidades sociopolíticas, recorremos às ponderações de Virilio (1993). Preocupado com a confusão entre o sensível e o inteligível promovida pela crescente ocupação telemática e videoperformativa dos espaços urbanos sustentada em interesses político-institucionais, notava que ela promovia uma "desregulamentação das aparências" (VIRILIO, 1993, p.23) capaz de conduzir a desvios de diagnóstico catastróficos. O que ele propõe? Que coloquemos nosso pensamento em estado de ebulição, como a água pouco antes da fervura. É este o pensamento crítico capaz de enfrentar as crises do real, dos sistemas políticos autofágicos e dos regimes de pensamento auto-celebratórios e autorreferentes. É esta a ebulição epistêmica que pode, metodologicamente falando, evitar erros de ótica, e eticamente, equívocos de conduta.

E o que isto tem a ver com ciência e com campo acadêmico? A compreensão do produtivismo como adição libidinal-racionalista. Algo contra produzir em volumes consideráveis? Obviamente não. Que se produza conhecimento de qualidade, tanto em larga escala quanto o que demanda temporalidade lenta e contínua. Que se faça valer o investimento de dinheiro público nesta produção, de modo que a responsabilidade cidadã não se confunda, mas compatibilize-se com o compromisso intelectual e os parâmetros científicos. Nossa desconfiança recai sobre os êxtases esquizofrênicos e alienantes que conduzem a vontade de poder (produzir) a lugar mais determinante que a qualidade 
do que se produz, assim como o raciocínio calculista operacionaliza decisões de pesquisa e pode permitir que políticas científicas tornem-se vulneráveis a negociatas e favorecimentos, mesmo que para isto se sacrifiquem temas e reputações ${ }^{5}$.

Sensível a cenários friccionais, Rincón (2015) se utiliza do conceito de bastardia para compreender a constituição comunicacional do real, e para poder analisar sem dogmatismos ou purismos elitistas as formas moventes deste mesmo real, bem como a potência de produção de materialidades que, cada vez mais, desde os anos 70, se dá a partir dos processos de comunicação social. Não há em Rincón o desejo de resguardar o pensamento do mundo das coisas, sejam estas tecnicidades, formas massivas ou narrativas do entretenimento. Rincón e Amado (2015) valem-se justamente das novas cenas e ambiências comunicacionais - tecnológicas, colaborativas, descentralizadas, pós-massivas, impuras - para lançar uma dura e irônica crítica aos emuladores das culturas midiáticas contemporâneas, de seus produtos e materialidades. O bastardo como chave conceitual leva a observar a convivência negociada, ambivalente, contaminada e tensa entre os planos da mediatização e aquele das mediações, bem como dos assujeitamentos e subjetivações.

Mas a bastardia não é apenas uma categoria diagnóstica. Ela pode ser assumida como recurso de contaminação voluntária, e é nesta direção que Rincón elabora conceitos como os de pop-lítica e de cidadanias celebrities. Nesta antropofagia do Sul, deglutimos e fagocitamos as colonizações sistêmicas que perfuram nossas subjetividades, devolvendo às máquinas bio-tecno-mediáticas nossas narrativas pagãs, nossas analogias barrocas, nosso sangue latino, nossa erótica ameríndia, nossa cosmogonia fronteiriça e sem lugar.

É justamente de negociação, ambivalência e tensão que fala a metáfora da fricção, dialogando com as tematizações do pornográfico feitas por Baltar (2013), com as erópticas e o pensamento estupefato, ambos propostos por Canevacci (2008), com as epistemologias do Sul e, como se propõe acima, com os estudos decoloniais. Ainda no campo da comunicação, a fricção também remonta e pode ser percebida em neologismos como o de tautismo de Sfez (1994), de pop-lítico de Rincón (2015), e em conceitos como o de popular-massivo de Janotti Junior (2006), de cosmopolitismo (pop)periférico de Prysthon (2009), de cultura pop de Soares (2014) ou de publicidade híbrida de Covaleski (2010).

A metáfora da fricção, dando uma volta a mais no parafuso da modernidade, retoma e distende o conceito de paradoxo, imprimindo ao "ser e não ser, ao mesmo tempo" característico das dinâmicas paradoxais, o movimento da tensão interna, que coloca os vetores em estado de contiguidade e de atrito. Presta-se, portanto, à análise de fenômenos e acontecimentos contemporâneos marcados pela convivência próxima e conflituosa entre planos que se pode à primeira vista compreender como excludentes. Entretenimento e ação política, por exemplo, tem sido uma das mais claras expressões

5 Recente e conceituada publicação internacional discute a contaminação do fazer científico por preceitos neoliberais. As autoras são enfáticas: produtivismo não garante nem excelência, nem brilhantismo. (The Slow Professor: challenging the culture of speed in the Academy. Maggie Berg e Barbara K. Seeber. University of Toronto Press, Toronto, 2016). 
desta situação. Não por acaso, Walter Benjamin, segundo aqui proponho, é, em uma chave barroca e híbrida, fundador de uma possível teoria das fricções entre sujeito(s)/ objeto(s), e disto nos falam suas noções de fantasmagoria e do sex-appeal do inorgânico.

Mas, sendo coerente às ênfases decoloniais, é preciso mencionar que fricções podem ser utópicas, mas são passíveis de cooptação. Os neologismos prosumidor e infotainment são exemplares da segunda forma. Não por acaso, neologismos como estes surgem e se disseminam como cogumelos no solo artificial do capitalismo ficcional.

Em síntese, foi proposta neste tópico a seguinte caracterização da metáfora da fricção:

a. Sendo uma noção periodizante e historicamente constituída ela remete à modernidade, em ao menos dois aspectos fundamentais: apresentando-se como radicalização das expressões paradoxais; e desmontando, por atrito e tensão, a tríade beleza/ordem/pureza, ao evocar o mal estar, a contaminação e a bastardia como operadores conceituais;

b. A fricção pós-moderna é da ordem da ebulição e da insubordinação epistêmica, problematizando articulações entre geopolítica do conhecimento e êxtase produtivista;

c. Em termos metódicos e conceituais, contempla a análise de fenômenos e processos comunicacionais complexos, dinâmicos e muitas vezes contraditórios, refratários a bases teóricas essencialistas e a abordagens dicotomizantes;

d. E, finalmente, fricções podem ser utópicas, mas também são passíveis de cooptação (muito embora, neste caso, entendamos que percam seu efeito de deslocamento de sentido).

\section{O capitalismo ficcional e as abstrações objetivadas}

Várias são as autoras e autores que se dedicam a análises do capitalismo contemporâneo considerando a participação fundamental que as indústrias, não da inconsciência, mas da representação desempenham na sustentação das lógicas do capital. Arlindo Machado (1984), em seu clássico livro A ilusão especular, detalha muito precisamente a centralidade da fotografia para compreendermos como a empreitada burguesa foi justamente uma batalha no plano da representação, das imagens e dos imaginários. Por razões como esta Jameson (1996) afirma que na pós-modernidade a lógica cultural é o capitalismo tardio, demonstrando, ainda, que a naturalização das imagens (como se fossem de fato tão naturais quanto árvores ou cachoeiras) é fator decisivo na transformação da esfera pública, na qual há

[o] aparecimento de um novo domínio da realidade das imagens, que é a um só tempo ficcional (narrativo) e factual (até as personagens dos seriados são 
percebidas como estrelas reais, com 'nomes próprios' e com histórias externas que precisamos conhecer), e que, agora - como a antiga 'esfera da cultura' torna-se semi-autônoma, e paira acima da realidade. (JAMESON, 1996, p.283).

E assim se dá no seio do capitalismo e das indústrias culturais uma configuração paradoxal que muitos ainda não logram perceber. Já o antevira Edgar Morin (2018), quando nos anos 60 detecta ao mesmo tempo o auge e a irreversível crise da cultura de massa. Ora, o raciocínio é lógico: a produção de representações em larga escala e contando com audiências cada vez mais complexas e multifacetadas, gera exatamente, como se nota posteriormente não só no argumento de Jameson (1996), mas de vários outros, uma crise da representação. A espetacularização da política, anunciada por críticos da pós-modernidade há mais de duas décadas, é apenas parte do imbróglio simbólico e institucional em que nos metemos.

Rocha (2010) atenta à economia política da publicidade - potente narrativa do capital - nota como valores enaltecidos por determinadas marcas fazem eco a marcos da política econômica nacional e, em termos macro, às dinâmicas neoliberais, transformando peças publicitárias em verdadeiros modalizadores do cotidiano, sempre muito afetuais, sempre com um apelo emocional que se sobrepõe, enquanto estratégia, a instâncias mais objetivas ou objetiváveis, mas que, justamente assim, materializam-se sutis e sedutores no dia-a-dia dos cidadãos-consumidores. Desde outra perspectiva analítica, Pelbart (2000) também irá insistir nas implicações de um capitalismo que suprime a externalidade, investe pesado na mercantilização das subjetividades e promove uma videoclipização do globo.

Insistindo em uma leitura biopolítica radical, Preciado (2014) descreve a articulação de duas forças: de um lado, as indústrias da medicamentalização do self, de outro, as formas pornográficas, não só das produções audiovisuais, mas da cultura como um todo. É esta agência combinatória que para ele contextualiza historicamente a conformação daquela que nomeia a sociedade farmacopornográfica. "No capitalismo farmacopornográfico", afirma Preciado (2014, p.50), "o desejo sexual e a enfermidade dividem uma mesma plataforma de produção e cultivo: não existem sem suportes técnicos, farmacêuticos e mediáticos capazes de materializá-los". Assim, ele prossegue, apesar de
[...] estarmos acostumados a falar de sociedade de consumo, os objetos que consumimos são o confete sólido de uma produção virtual psicotóxica. Consumimos ar, sonhos, identidade, relação, alma. Este novo capitalismo farmacopornográfico funciona na verdade graças à gestão biomediática da subjetividade, através de seu controle molecular e da produção de conexões virtuais audiovisuais. (PRECIADO, 2014, p. 48; tradução nossa).

Freire Costa (2004) já tinha observado a emergência de patologias da publicização características da nova ordem pública e do desequilíbrio da economia da afetividade provenientes da moral do espetáculo. É esta moral que nos constrange a uma busca 
constante por um corpo capaz de retratar uma imagem ideal do eu e, mais ainda, a um corpo-imagem capaz de performar permanentemente a felicidade. Neste caso, os objetos não são o que realmente importa, nem a frustração em não possuí-los exatamente o motor da insatisfação. O núcleo do mal-estar e da moral consumista é, na verdade, a prescrição de um modo correto de se satisfazer. Fetichistas, bulímicos e produtivistas empedernidos encontram-se nesta antessala do gozo excessivo que antecede a manutenção da falta compulsória. E, assim, para lembrar Jean Baudrillard (1992), o jogo da sedução é apenas a reiteração do complexo de Don Juan: nunca terei tudo que desejo, mas nunca deixarei de buscar, como um autômato, a uma nova conquista que deverei, forçosamente, abandonar.

Chegamos aqui ao cerne da questão: o capitalismo ficcional prescreve que se considere real, natural e a-histórico o que é cultural e contingente. Taussig, leitor de Marx e Benjamin, propõe que este capitalismo vem historicamente buscando anular a percepção da cultura como lugar de tensões e arbitrariedades, mas também de resistências e mutações. E é assim que "a aparência animada das mercadorias evidencia a aparência coisificada das pessoas e ambas dissolvem-se quando a inspiração mercantil das definições de homem e sociedade é ressaltada" (TAUSSIG, 2010, p.30). Esta teria sido a referência de Marx ao eleger o fetichismo da mercadoria como um núcleo de sua crítica à cultura capitalista, em que mercadorias são coisas e não-coisas, e como não-coisas tornamse reguladoras e modeladoras das relações sociais. Em Adorno (1985), o desdobramento do conceito levará ao fetichismo da mercadoria cultural e à crítica às formas burguesas de produzir não apenas cultura, mas conhecimento. Preocupações desta ordem estarão presentes para Debord (1997), quando em meados da década de 70 afirma que na cultura do espetáculo não existem mais relações sociais, mas relações mediadas por imagens. Três décadas mais tarde, a temática será problematizada nas leituras de Canevacci (2008) sobre os fetichismos visuais que decalcam as cidades contemporâneas, e que não seriam nem alienantes, nem dotados de perversidade, mas demandariam do olhar desdobrar-se em eróptica.

Na genealogia da ficcionalidade realizante proposta por Taussig (2011, p.31) temos que em "sua forma mercantil, a sociedade engendra tal realidade ficcional, assim, somos obrigados a lidar e a compreender o mundo a partir desses símbolos e abstrações", cabendo ao crítico "que pode se manter fora desse sistema conformador mútuo, [perceber que] a forma monetária do mundo das mercadorias é o signo que obscurece as relações sociais escondidas nas abstrações que a sociedade considera fenômenos naturais." (2011, p. 32). Finalmente, "essa ficção socialmente necessária é um lugar comum que fundamenta o ar de naturalidade ficcional das identidades das quais a sociedade depende e que garante seus conceitos de objeto e de objetividade." (2011, p.54). O "mercado torna-se, assim, a garantia de $[\ldots .$.$] coerência espiritual [dos sujeitos]":$

As bases de subsistência estabelecidas pelo mercado tornam-se, na verdade, um reiterado ritual cotidiano pela sobrevivência que-como ocorre com todos os ritos - agrupa feixes de sentido, antes desconectados, em uma rede de associações à primeira vista coerente e natural. (TAUSSIG, 2011, p. 54). 
Observando o desenvolvimento do neoliberalismo, Lazzarato (2014) defende que ele se desdobrou na "ubiquidade da subjetivação empreendedora" (LAZZARATO, 2014, p. 14), gerando existências compráveis e submetendo nossa autonomia subjetiva ao poder pastoral de maquinismos diagramáticos. Esta geografia ficcional pode levar a segregações territoriais muito concretas, como aquelas às quais se refere Dunker (2015), ao apontar a lógica condominial típica da sociedade brasileira, na qual os de dentro temem e excluem os de fora. Neste contexto, a "globalização do capital gerou também uma globalização das maneiras de sofrer". E, assim, ele pergunta: "A forma-mercadoria do sofrimento prepara o terreno ou lida com os efeitos secundários da devastação das formas de vida tradicional?" (DUNKER, 2015, p. 25).

O capital como operador semiótico participa desta gestão do mal-estar e faz dele uma doença,

[...] inserindo-a em um circuito que vai da propaganda, da divulgação e do consumo de experiências de bem-estar até a aliança entre pesquisa universitária, laboratórios farmacêuticos e gestão da saúde mental. [...] Até que ponto o uso de substâncias que aumentam a performance laboral, sexual ou educacional está de fato suprimindo um sintoma e onde começa a extração de mais-valor comportamental? (DUNKER, 2015, p. 23).

Esta é uma boa questão para confrontar o canto das sereias do capitalismo cognitivo, que faz do culto ao desempenho o grande personal trainer de nossas potências intelectuais.

\section{Devorando o capitalismo cognitivo para não ser por ele devorado}

Assumo, nestes últimos argumentos, uma declaração de bastardia, a defesa da contaminação pelos fluxos dos corpos; pelos fluidos erópticos e pela impureza. A metáfora da devoração assume, em minha escrita, uma função igualmente provocadora; a defesa de uma necessária autocrítica e de uma imprescindível auto-ironia, para não nos iludirmos com fundamentalismos do saber nem com vaidades cognitivas. Gostaria de lembrar Silva (2009), quando propõe que

[o]s números [...] não dizem muito sobre a realidade das estruturas de poder e os aspectos psíquicos, sociais e políticos que envolvem a pressão para publicar. Os dados estatísticos são frios, próprios do pensamento positivista imperante que deseja quantificar tudo. Mas como quantificar a angústia, o sofrimento humano dos que estão submetidos à pressão para publicar? Como quantificar o que sente aquele que não consegue se adequar a esta exigência? (SILVA, 2009, p.2)

A conformação produtiva pós-industrial (capitalista) com a respectiva nomeação auto-imputada (cognitivo, criativo, informacional), apresenta de modo sedutor os riscos do que Benjamin (2006) associava à ideia da fantasmagoria em seu negativo, 
Adorno (1985) conceituou como fetichismo do conhecimento e Preciado (2014) - analisando o tecnocapitalismo avançado - define como lógica farmacopornográfica. Neste contexto, a grande fricção destina-se a dois polos: celebrização do conhecimento, de um lado; politicidade decolonial, de outro. Tensionando estes vetores, a produtividade intelectual encontra, segundo a proposta que trazemos ao debate, uma condição de possibilidade auspiciosa para escapar às aduanas produtivistas sem abrir mão do rigor ou furtar-se ao debate; ela o faz, muito objetivamente, através de programas de pesquisa que se sustentam em práticas, políticas, de subjetivação.

A fricção do capitalismo ficcional busca, a contrapelo, uma vigilância epistêmica e um recuo de subjetivação. Com ela pretendi distinguir a produtividade científica da sedução produtivista. Ou seja, não basta avaliar, mas é imperativo analisar as dinâmicas, as lógicas que regem a produção de métricas e critérios de avaliação. Aqui, a compreensão da distinção clama pela consciência do caráter coletivo e do compromisso social que deve dar suporte e perspectivar as políticas e os programas de pesquisa. Devoremos a pulsão essencialista e individualista que emerge do dito capitalismo cognitivo, upload high-tech e empreendedor do capitalismo ficcional. E o façamos no âmbito da politicidade e da subjetividade. "De que servem as partículas elementares quando quero me enforcar de desespero?", perguntou-se certa vez Feyerabend (1977), alertando para a vontade de poder atrelada a determinadas instâncias do fazer científico implicadas não em descobertas, não em olhar para o humano, mas, sim, em dogmaticamente apresentar ao mundo verdades universais e incontestáveis. E não faltam arautos e aduaneiros destas verdades. A linhagem dos pareceres eclesiásticos sinaliza o cruel vaticínio diagnóstico que pode atingir o campo científico. Felizmente não é ela a única que temos.

Rosamaria Luiza de Melo Rocha é professora do programa de pós-graduação em Comunicação e Práticas de Consumo da ESPM.

rlmrocha@uol.com.br

\section{Referências}

AMADO, A.; RINCÓN, O. La reinvención de los discursos o cómo entender a LOS BÁRBAROS DEL SIGLO XXI. In: AMADO, A.; RINCÓN, O. La comunicación en mutación. Bogotá: Centro de Competencia en Comunicación para América Latina, 2015.

ADORNO, T.; HORKHEIMER, M. Dialética do esclarecimento. Rio de Janeiro: Zahar, 1985.

BALTAR, M. Femininas Pornificações. In. BRAGANÇA, M. eTEDESCO, M. (org). Corpos em Projeção. Rio de Janeiro, 7Letras, 2013.

BAUDRILLARD, J. Da sedução. Campinas: Papirus, 1992.

BENJAMIN, W. Passagens. Belo Horizonte: Editora da UFMG, 2006.

BAUMAN, Z. O mal estar da pós-modernidade. Rio de Janeiro: Jorge Zahar, 1998. 
CANEVACCI, M. Fetichismos Visuais. São Paulo: Ateliê Editorial, 2008.

COSTA, J. O vestígio e a aura. Rio de Janeiro: Garamond, 2004.

COVALESKI, R. Publicidade Híbrida. Curitiba: Maxi Editora, 2010.

DEBORD, G. A sociedade do espetáculo. Rio de Janeiro: Contraponto, 1997.

DELEUZZE, G. e GUATTARI, F. O anti-Édipo. São Paulo: Editora 34, 2011.

DUNKER, C. Mal-estar, sofrimento e sintoma. São Paulo: Boitempo, 2015.

FEYERABEND, P. Contra o método. Rio de Janeiro: Francisco Alves, 1997.

FOUCAULT, M. As palavras e as coisas. São Paulo: Martins Fontes, 1999.

FRANÇA, V. e PRADO, J. L. A. Comunicação como campo de cruzamentos, entre as estatísticas e o universal vazio. Questões Transversais. Revista de Epistemologias da Comunicação. São Leopoldo, vol. 1, n. 2, julh.-dez. 2013.

JAMESON, F. Pós-modernismo. São Paulo: Ática, 1996.

JANOTTI JR, J. Por uma análise midiática da música popular massiva. Uma proposição metodológica para a compreensão do entorno comunicacional, das condições de produção e reconhecimento dos gêneros musicais. Revista E-Compós, vol. 6, 2006. p. 1-15.

LADLE, R. et al. Assessing insularity in global science. Scientometics. (2012) 93: 745. https://doi. org/10.1007/s11192-012-0703-z

LAKATOS, I. História da ciência e suas reconstruções racionais. Lisboa: Edições 70, 1998.

LAZZARATO, M. Signos, máquinas, subjetividades. São Paulo: SESC/n-1, 2014.

MACHADO, A. A ilusão especular. São Paulo: Brasiliense, 1984.

MIGNOLO, W. Desobediência epistêmica: a opção descolonial e o significado de identidade em política. Revista Gragoatá, n. 22, p. 11-41, 1 sem. 2007.

MORIN, E. Cultura de massas no século XX. São Paulo: Forense, 2018.

PELBART, P. A vertigem por um fio. São Paulo: Iluminuras, 2000.

PRECIADO, P. Texto yonqui. Cidade Autônoma de Buenos Aires: Paidós, 2014.

PRYSTHON, A. Tropicália: O cosmopolitismo pop do Terceiro Mundo. Revista Graphos. v.11, n.1, 2009. p. 129-143.

RANCIÈRE, J. O espectador emancipado. São Paulo: Martins Fontes, 2014.

RINCÓN, O. Lo popular en la comunicación. Culturas bastardas + ciudadanías celebrities. In: AMADO, A. e RINCÓN, O. La comunicación en mutación. Bogotá: Centro de Competencia en Comunicación para América Latina, 2015.

ROCHA, M. A nova retórica do capital. São Paulo: Edusp, 2010.

SANTOS, S. A naturalização do produtivismo acadêmico no trabalho docente. Revista Espaço Acadêmico. Maringá, n. 110, jul. 2010. p. 147-154.

SFEZ, L. Crítica da comunicação. São Paulo: Loyola, 1994. 
SERRES, M. Tempo de crise. Rio de Janeiro: Bertrand Brasil, 2017.

Narrativas do humanismo. Rio de Janeiro: Bertrand Brasil, 2015.

SILVA, A. Produtivismo no campo acadêmico: o engodo dos números. Revista Espaço Acadêmico, v. 9, n. 100, p. 1-5, Set. 2009. Disponível em: http://www.periodicos.uem.br/ojs/index.php/ EspacoAcademico/article/view/8148/4571 Acessado em: 05 de Junho, 2017.

SOARES, T. Abordagens teóricas para estudos sobre cultura pop. LOGOS 41 - Cidades, Culturas e Tecnologias Digitais. Rio de Janeeiro v. 2, n. 24, 2014.

TAUSSIG, M. O diabo e o fetichismo da mercadoria na América do Sul. São Paulo: Ed. Unesp, 2010.

VIRILIO, P. O espaço crítico. Rio de Janeiro: Editora 34, 1993.

ZANDONÁ, C, et al. Produtivismo acadêmico, prazer e sofrimento. Erechim, v. 38, n.144, p. 121 130, dez. 2014. 